\title{
Psalmy Dawidowe (Gdańsk 1616): przyczynek do recepcji Katechizmu Heidelberskiego w Polsce ${ }^{1}$
}

\begin{abstract}
Streszczenie. Artykuł jest próbą określenia okoliczności powstania i ewentualnych źródeł katechizmu zamieszczonego w składzie Psalmów Dawidowych (Gdańsk 1616) Katechizmu Heidelberskiego, zwanego również Katechizmem Palatynatu, wydanego w 1563 roku. Redaktorzy polscy w trakcie pracy translatorskiej korzystali z linii tzw. psałterzy heidelberskich (Heidelberg 1567, 1573, 1575; Neustadt 1584; Herborn 1595, 1598, 1609; Amberg 1604; Düsseldorf 1612), które zawierały niemieckojęzyczną wersję Psatterza genewskiego autorstwa tłumacza i wykładowcy prawa na Uniwersytecie w Królewcu Ambrosiusza Lobwassera (Lipsk 1573) oraz połączony ze skróconą Ordynacja kościelna dla Palatynatu i wyborem modlitw Katechizm Heidelberski. Inicjatywa przekładu katechizmu należała do przedstawicieli Jednoty Braci Czeskich, którzy nie wiedzieli o już istniejącym i używanym w praktyce szkolnej polskim tłumaczeniu (Wilno 1605). Świadczy to o tym, że przedstawiciele różnych odłamów reformacyjnych w Rzeczypospolitej nie zawsze byli dobrze obeznani ze wzajemnym dorobkiem wydawniczym. Polecany przez ustawodawstwo synodalne Katechizm Heidelberski staje się z czasem podstawą nauczania w Rzeczypospolitej zarówno w jednotach reformowanych, jak i u braci czeskich.
\end{abstract}

SŁowA KLUczowe: piśmiennictwo reformacyjne w Rzeczypospolitej, psałterz Ambrosiusza Lobwassera, polskie przekłady Katechizmu Heidelberskiego i ich recepcja.

W 1616 roku w gdańskiej oficynie Andrzeja Hünefelda ukazała się kolejna edycja Psalmów Dawidowych: Przekładania X. Macieia Rybinskiego na melodye Psalmom francuskich urobionych ${ }^{2}$. W datowanej na 1 stycznia przedmowie do sędziego ziemi puckiej Ernesta Krokowskiego (1575-1631) wydawcy psałterza - zdaniem Karola Estreichera brał w tym udział również

${ }^{1}$ Artykuł powstał $\mathrm{w}$ ramach stypendium badawczego Herder-Institut w Marburgu (2013).

${ }^{2}$ Egz. Biblioteki Kórnickiej (sygn. 1426; mf BN 3647) i Herzog August Bibliothek, Wolfenbüttel (dalej - HAB, sygn. 1244.5.Theol.8oㅜ). 
senior braci czeskich w Wielkopolsce Jan Turnowski (1567-1629) ${ }^{3}$ opisują zawartość dzieła. Większą część wydania stanowią psalmy, które „Maciey Rybinsky [...] podług melody francuskych na Polski ięzyk przełożył”, a „k tey sławney pracy [...] X. Daniel Mikołaiewsky Summarium każdego psalma przyłączył” (k. 7-8). Do tego, "aby też przy sporządzeniu kościoła / szkoły nie zapomniano / na pożytek młodości y prostych ludzy / przyłączony iest zwysz przemienioney robocie Catechizm / ktory do te czasy tylko w łacyńskym y Niemieckym ięzyku był wydany: ktorego Catechismu przekładanie / gdysz to / iako rzeczono / dla dziecy y prostych ludzy a nie dla uczonich y iuż w wierze doskonałych / przełożono / nie tak wielce ozdobność mowy używano iako to samo / iakobysie nayprościey / y zwykłemy / nayrozumnieyszemy słowy przełożyło" (k. 8). Z przedmowy zatem wynika, że dołączony do psalmów i przeznaczony do użytku szkolnego i dla prostych wiernych katechizm drukowany był po raz pierwszy w języku polskim.

Psalmy z argumentami obejmują większą część druku (do s. 392). Po psalmach (na s. 393) zamieszczony jest starotestamentowy kantyk z Księgi Wyjścia (20, 2-17): Dziesięcioyo [!] Boży przykazanie na melodie Psalmu 140 (incipit: „Słuchai Jzraelu tey mowy / Nie zatwardzai serca swego / Tak Bog swemi własnemi słowy / Mowić raczy do każdego") i na s. 395 nowotestamentowy kantyk Symeona (na podstawie Łk 2, 29-32). Po rejestrze z osobną kartą tytułową i osobną paginacją następuje wspomniany wyżej Katechizm albo krotka nauka wiari swiętei krześciańskiey powśechnei iako bywa w kraiach Niemieckich y z Ceremoniamy kościełnemy odprawowana teras niedawno z niemieckiego ięzyka na polsky przełożona. Psal. 8. Ex ore infantium et lactentium comparasti tibi laudem (podkr. - M.K.). Po katechizmie (na s. 78) rozpoczyna się zatytułowany dość ogólnie rozdział Modlitwy, w którego skład wchodzą: szereg modlitw przed kazaniem i po kazaniu (do jednej z nich dołączone są: spowiedź powszechna, tekst Dekalogu i błogosławieństwo na podstawie Lb 6), Forma albo sposob krzczenia (s. 105-118), Przygotowanie do stotu pańskiego i Sposob odprawowania wieczerzi Pańskiey (s. 118-142), Forma albo sposob oddawania w Matżeństwo wstępuiacych (s. 142-155), O nawiedzeniu chorych (s. 155-167), szereg modlitw porannych, wieczornych, przed jedzeniem i po używaniu pokarmów, Tablica domowa, to iest, z pisma swiętego nauka [jak] się każdy w stanie swoim ma sprawować (s. 177-186) i Symbolum, albo wyznanie wiary swiętego Athanasiusza (s. 187-191).

Zamieszczony jako dodatek do psalmów katechizm z modlitwami i formami sprawowania sakramentów oraz poszczególnych obrzędów to wydany w 1563 roku na polecenie elektora Palatynatu Reńskiego

${ }^{3}$ K. Estreicher, Bibliografia polska, t. 15, Kraków 1897, s. 75. 
Fryderyka III Wittelsbacha (1515-1576) Katechizm Heidelberski, zwany również Katechizmem Palatynatu. Ułożony przez teologów o orientacji filipistyczno-kalwińskiej i sformułowany w tonie ugodliwym wobec różnych odłamów protestanckich katechizm stał się w czasach późniejszych podstawowym pismem konfesyjnym nie tylko dla Palatynatu ${ }^{4}$. Jego trzecią, nieco zmienioną edycję opublikowano pod koniec 1563 roku w składzie Kirchenordnung Palatynatu ${ }^{5}$. Od tego czasu drukowano Katechizm Heidelberski prawie zawsze w połączeniu z Ordynacja kościelna $\mathrm{w}$ jej pełnej lub znacznie skróconej wersji. Tłumaczy to, dlaczego wydawcy Psalmów Dawidowych z 1616 roku odtwarzają go właśnie w takim składzie, choć zarówno ewangelicy reformowani w Rzeczypospolitej, jak i Jednota Braci Czeskich mieli w tym okresie do dyspozycji własne formy sprawowania sakramentów - odpowiednio w Porządku Nabożeństwa (edycja z 1602 roku i jej rewidowana wersja z 1614 roku) i Agendzie (Kralice 1612) .

Zamykająca Psalmy Dawidowe i ułożona z cytatów biblijnych Tablica domowa też należała do części składowych wczesnych wydań Katechizmu Heidelberskiego. Różni się ona nieco od słynnej Haustafel, którą w 1529 roku zamieścił w Małym Katechizmie Marcin Luter, i zawiera przepisy skierowane do zwierzchności świeckiej (Ps 2, 10-12; Iz 1, 16-17), sędziów (Wj 18, 21-22; 2Krn 19, 6-7), poddanych (Rz 13, 1-6; 1P 2, 13-14), mężów (Ef 5, 25; Kol 3, 19; 1P 3, 7), żon (Ef 5, 22-23; Kol 3, 18; 1P 3, 1-6), rodziców (Pwt 6, 6-7; Prz 23, 13-14, 24; 19, 18; 29, 15; Syr 7, 25; 30, 11; Ef 4, 6; Kol 3, 21), dzieci (Ef 6, 1-3; Kol 3, 20), pracowników i służących (Ef 6, 5-8; Kol 3, 22-24; 1P 2, 18), gospodarzy (Ef 6, 9; Kol 4, 1), pospolitej młodzi (1Kor 6, 9-10; 1P 5, 5-7), panienek (1Kor 7, 32-35), wdów (1Tm 5, 5-7, 13), a także summę Zakonu Bożego, czyli podwójne przykazanie miłości i summę

${ }^{4}$ Nie wchodząc w nieco zawiłą historię powstania tego katechizmu, zaznaczmy tylko, że nawet sprawa jego autorstwa nie jest do końca rozstrzygnięta. Zob. L.D. Bierma, Olevianus and the Authorship of the Heidelberg Catechism: Another Look, "Sixteenth Century Journal" 1982, t. 13, nr 4, s. 17-27; idem, "Vester Grundt" and the origins of the Heidelberg Catechism, w: Later Calvinism. International Perspectives, red. W.F. Graham, Kirksville 1994, s. 289-309; I.J. Hesselink, The Dramatic Story of the Heidelberg Catechism, w: Later Calvinism..., s. 273-288; F.H. Klooster, The Priority of Ursinus in the Composition of the Heidelberg Catechism, w: Controversy and Conciliation. The Reformation and the Palatinate 1559-1583, red. D. Visser, Allison Park 1986, s. 73-100; D. Visser, Zacharias Ursinus (1534-1583). Melanchthons Geist im Heidelberger Katechismus, w: Melanchthon in seinen Schülern, red. H. Scheible, Wiesbaden 1997, s. 374.

${ }^{5}$ Die Evangelischen Kirchenordnungen des XVI. Jahrhunderts, red. E. Sehling, t. 14: Kurpfalz, Tübingen 1969, s. 333-408 (tekst ordynacji), s. 342-375 (katechizm).

${ }^{6}$ D. Petkūnas, Holy Communion Rites in the Polish and Lithuanian Reformed Agendas of the 16th and Early 17th Centuries, Klaipeda 2007. 
Ewangelii na podstawie J 3, 16 i 1Tm 1, 15-16, skierowane do wszystkich wiernych ${ }^{7}$. Tablica domowa w takim składzie sięga Ordynacji kościelnej z 1533 roku dla Brandenburgii-Norymbergi i z 1543 roku dla Księstwa Pfalz-Neuburg; w Kirchenordnung dla Palatynatu Reńskiego spotykamy ją po raz pierwszy w 1556 roku$^{8}$.

Redaktorzy Psalmów Dawidowych z 1616 roku zaznaczają w przedmowie, że w trakcie pracy translatorskiej korzystano z edycji niemieckiej. Taki właśnie układ psałterza, czyli połączenie go z Katechizmem Heidelberskim, ordynacją kościelną i wyborem modlitw spotykamy po raz pierwszy w Psalmen Davids und andere Geistliche Lieder sampt dem Christlichen Catechismo, Kirchenceremonien und Gebeten (Heidelberg, Johannes Mayer, 1567) ${ }^{9}$.

Wydanie psalmów razem z ustawą było logiczne dla ewangelików reformowanych, bo psalmy stanowiły u nich ważną część nabożeństwa. Jednym z najwcześniejszych przykładów takich edycji jest psałterz z 1566 roku dla wspólnoty w Londynie, który ukazał się razem z Formulier kerckendienstes ${ }^{10}$.

W kolejnych wydaniach heidelberskich z 1573 i 1575 roku $^{11}$ wcześniejsze tłumaczenie psalmów zostało zastąpione niemieckojęzyczną wersją Psałterza genewskiego autorstwa tłumacza i wykładowcy prawa na Uniwersytecie w Królewcu Ambrosiusza Lobwassera (1515-1585). Pierwsza edycja psałterza ukazała się w 1573 roku $^{12}$; większy zaś rozgłos zyskała druga, poprawiona przez samego Lobwassera (Lipsk, Hanss Steinman,

${ }^{7}$ Por. u Lutra: dla biskupów, proboszczów i kaznodziejów; co winni chrześcijanie nauczycielom i duszpasterzom swoim; o zwierzchności świeckiej; co winni są poddani zwierzchności; dla mężów; dla żon; dla rodziców; dla dzieci; dla pracowników i pracownic domowych i robotników; dla przełożonych; dla młodzieży; dla wdów; dla wszystkich w zborze (Księgi wyznaniowe Kościoła Luterańskiego, Bielsko-Biała 1999, s. 53-55).

${ }^{8}$ Die Evangelischen Kirchenordnungen..., t. 14, s. 127-130; Bekenntnisschriften und Kirchenordnungen der nach Gottes Wort reformierten Kirche, red. E.F.K. Müller, Zürich 1987, s. 181-184.

${ }^{9}$ H. Walter, Der Heidelberger Katechismus im konfessionspolitischen Kräftespiel seiner Frühzeit. Historisch-bibliographische Einführung der ersten vollständigen deutschen Fassung, der sogenannten 3. Auflage von 1563 und der dazugehörigen lateinischen Fassung, Zürich 1983, s. 36, 38.

${ }^{10} \mathrm{~J}$. Becker, Gemeindeordnung und Kirchenzucht. Johannes a Lascos Kirchenordnung für London (1555) und die reformierte Konfessionsbildung, Leiden-Boston 2007, s. 285.

${ }^{11}$ Korzystam z edycji z 1575 roku (egz. ze zbiorów Bibliotheca Palatina, HAB, mikrofisza 1518: F731-F734).

${ }^{12}$ Należy obecnie do druków bardzo rzadkich. Patrz jej opis w: Ph. Wackernagel, Bibliographie zur Geschichte des deutschen Kirchenliedes im XVI. Jahrhundert, Frankfurt am Main 1855, s. 380-381. 
$\left.1576^{13}\right)$. Przeważnie ona używana była w czasach późniejszych we wspólnotach reformowanych w Niemczech i w niemieckojęzycznej Szwajcarii ${ }^{14}$.

Przekładając Psałterz genewski, Lobwasser zostawił obydwa zamieszczone po psalmach kantyki - z Księgi Wyjścia (Les Commandements de Dieu) i pieśń Symeona (Le cantique de Siméon) ${ }^{15}$. Rymowany Dekalog autorstwa Kalwina (incipit: „Oyons la Loy que de sa voix”) ukazał się po raz pierwszy w Predigtgottesdienst (Straßburg 1538), następnie w zbiorze psalmów Aulcuns pseaulmes et cantiques mys en chant (Straßburg 1539) ${ }^{16}$. Zamieszczona w Psalmach Dawidowych wersja Dekalogu nie jest dosłownym tłumaczeniem ani kantyku Kalwina, ani pieśni autorstwa Lobwassera (incipit: „Erheb dein Hertz, thu auff dein Ohren” ${ }^{17}$ ). Do każdego psalmu Lobwasser dołączył krótkie wezwanie modlitewne, które czasami pomijano w późniejszych przedrukach - brak ich i w polskim wydaniu z 1616 roku.

Do czasu ukazania się w drukarni Hünefelda Psalmów Dawidowych opublikowano razem 74 edycje psałterza Lobwassera. Drukowano go często jako samodzielny dodatek do Biblii, w której z kolei zamieszczano całkiem inną wersję psalmów.

Nie da się z całą pewnością stwierdzić, z jakiej (albo jakich?) edycji korzystano w trakcie układania polskiej wersji z 1616 roku. Najbardziej interesują nas przypadki, w których psałterz ukazywał się bez części kancjonałowej, bo w wydaniu Hünefelda brak jakichkolwiek pieśni. Nie znaczy to bynajmniej, że polscy redaktorzy nie mogli korzystać z poszerzonych przedruków psałterza.

Tłumaczenie samych psalmów zostało sporządzone znacznie wcześniej. W literaturze są rozbieżności co do datowania najwcześniejszej edycji przekładu seniora Jednoty Braci Czeskich w Wielkopolsce Macieja Rybińskiego (1566-1612) ${ }^{18}$. Po raz pierwszy ukazał się on w 1598 roku; istniała być

${ }^{13}$ A. Lobwasser, Der Psalter deß Königlichen Propheten Davids, red., komentarz E. Grunewald, H.P. Jürgens, współpraca D. Gutknecht, L. Kessner, t. 1-2, Hildesheim-Zürich-New York 2004.

${ }^{14}$ I. Scheitler, Der Genfer Psalter im protestantischen Deutschland des 17. und 18. Jahrhunderts, w: Der Genfer Psalter und seine Rezeption in Deutschland, der Schweiz und den Niederlanden 16.-18. Jahrhundert, red. E. Grunewald, H.P. Jürgens, J.R. Luth, Tübingen 2004, s. 263.

15 A. Lobwasser, op.cit., t. 2, s. 47.

${ }^{16}$ B.A. Föllmi, Calvin und das Psalmsingen. Die Vorgeschichte des Genfer Psalters, „Zwingliana" 2009, t. 36, s. 74-78.

${ }_{17} \mathrm{Ph}$. Wackernagel, Das deutsche Kirchenlied von der ältesten Zeit bis zu Anfang des XVII. Jahrhunderts, t. 4, Leipzig 1874, s. 872.

${ }^{18}$ Psałterz Rybińskiego jest wiernym przekładem psalmów francuskich; tylko niektóre psalmy z niewielkimi zmianami zostały przejęte od Jana Kochanowskiego. Rybiń- 
może wcześniejsza publikacja ${ }^{19}$. W literaturze niemieckojęzycznej spotykamy wzmianki o nieznanej bibliografii edycji z 1600 roku $^{20}$. Janusz Pelc natomiast uważa, iż tłumaczenie Rybińskiego ukazało się drukiem po raz pierwszy w oficynie S. Sternackiego dopiero w 1605 roku $^{21}$. W Encyklopedii Orgelbranda wymieniono także przedruki psałterza - Kraków 1604 i Gdańsk 1608 (dwukrotnie)22. Wszystkie one nie zawierają jeszcze poprawek Jana Turnowskiego, ujętych dopiero w toruńskiej edycji z 1617 roku.

O zamiarach przetłumaczenia "katechizmu niemieckiego" wspomniano podczas synodu w Ostrorogu (14-18 maja 1609), na którym między innymi postanowiono wydać ponownie nieco poszerzoną wersję kancjonału Krzysztofa Kraińskiego: „O Katechizmie ta konkluzyja uczyniona, żeby katechizmek mniejszy z przydaniem symbolów i modlitew niektórych i piosneczek pogrzebowych bez omieszkania był wydrukowan w Rakowie, co się ma poruczyć br. Adamowi Ireneuszowi. Katechizmu niemieckiego podanie do druku poruczone br. Marcinowi

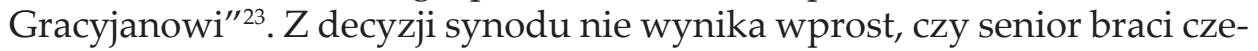
skich Marcin Gracjan Gertych (1568-1629) miał samodzielnie sporządzić polską wersję katechizmu, czy tylko nadzorować prace nad jego przekładem. Gertych w swoim dzienniku o tym tłumaczeniu nie wspomina ${ }^{24}$.

Do tej kwestii powrócono ponownie na konwokacji w Parcicach (1614?); z lakonicznego sformułowania postanowienia wynika, że tłumaczenie nie było jeszcze ukończone („Niemiecki katechizm br. Gracyjan sporządzi”25).

ski korzystał prawdopodobnie też z czeskiego tłumaczenia konseniora jednoty Jerzego (Jírí) Streyca (1536-1599), które powstało dla Biblii kralickiej (1579-1593/1594). Zob. R. Leszczyński, Rybiński, Maciej, w: Encyklopedia katolicka, t. 17, Lublin 2012, kol. 645. Ponadto brakuje badań szczegółowych dotyczących tego, czy Rybiński sięgał po Lobwassera.

${ }^{19}$ J. Zdanowicz, Psatterz Rybińskiego (wraz z wykazem polskich kancjonałów i psatterzy $z$ XVI w.), „Muzyka. Kwartalnik poświęcony historii i teorii muzyki oraz krytyce naukowej i artystycznej" 1957, nr 3 (6), s. 66.

${ }^{20}$ Der Genfer Psalter - eine Entdeckungsreise, red. P.E. Bernoulli, F. Furler, wyd. 2 zmien., Zürich 2005, s. 15-17.

${ }^{21}$ J. Pelc, Teksty Jana Kochanowskiego w kancjonatach staropolskich XVI i XVII wieku, "Odrodzenie i Reformacja w Polsce" 1963, t. 8, s. 241.

${ }^{22}$ F.M. Sobieszczański, Maciej Rybiński, w: S. Orgelbrand, Encyklopedia powszechna, t. 22, Warszawa 1866, s. 569.

${ }^{23}$ Akta synodów różnowierczych $w$ Polsce, oprac. M. Sipayłło, t. 4: Wielkopolska 1569-1632, Warszawa 1997, s. 199-200.

${ }^{24}$ Dziennik M.G. Gertycha, X.1608-31.VIII.1616, w: Akta synodów różnowierczych..., s. 377-389.

${ }^{25}$ Akta synodów różnowierczych..., s. 261. 
Jakkolwiek nie da się sprecyzować, z jakiego niemieckojęzycznego pierwowzoru korzystano w trakcie prac nad polskim przekładem, jest to druk, który ukazał się przed połową 1615 roku (przedmowa do Psalmów Dawidowych jest datowana na 1 stycznia roku następnego) i który należał najprawdopodobniej do linii psałterzy heidelberskich.

Kontynuacją tej linii po 1575 roku były wydania z oficyn Matthäusa Harnischa (zm. 1596) z Neustadt w Nadrenii $(1584)^{26}$, Christoffa Corvina (1552-1620) z Herborn w księstwie Nassau (159527, 159828, 160929), Michaela Forstera (zm. 1622) z Amberg $\left(1604^{30}\right)$. Wszystkie one, jak i Psalmy Dawidowe z 1616 roku przytaczają wierszowany Dekalog oraz pieśń Symeona i rezygnują z krótkich wezwań modlitewnych zamieszczonych przez Lobwassera po każdym psalmie; fragment ustawy kościelnej połączony jest z modlitwami i Tablica domowa i stanowi samodzielny rozdział Von dem Kirchen Gebett.

Co różni owe wydania od edycji Hünefelda? Z pięciu zamieszczonych na samym końcu symboli zostawił on tylko wyznanie wiary św. Atanazjusza i zrezygnował z modlitw uzupełniających ustawę kościelną. Do nowości należy również wzmianka w ustawie o wspólnym odmawianiu po kazaniu dziesięciu przykazań (s. 92, druga paginacja); edycje niemieckie zalecają w tym miejscu tylko odśpiewanie pieśni na cześć Pana. Recytacja Dekalogu w trakcie nabożeństwa nie należała w Kościołach protestanckich do rzadkości. Jedna z najwcześniejszych informacji pochodzi z ułożonego przez Johannesa Brenza Porzadku nabożeństwa w Halle z 1526 roku ${ }^{31}$ i Ustawy Kościelnej Bremy z 1529 roku $^{32}$. O istnieniu tej praktyki świadczy również La Manyere de faire prieres dla Genewy (1542) ${ }^{33}$, Agenda dla Norymbergi $(1545)^{34}$, Ustawa dla wspólnoty w Londynie $(1554)^{35}$ i dla hrabstwa Wertheim $(1555)^{36}$. W tradycji polsko-litewskiej wzmianki o odmawianiu

\footnotetext{
${ }^{26}$ Egz. HAB, sygn. 749.28 Theol (1).

${ }^{27}$ Egz. HAB, sygn. H: A $968^{\circ}$.Helmst.

${ }^{28}$ Egz. HAB, sygn. M: Tl 180.

${ }^{29}$ Mikrofisza HAB 1518: D159-D160.

${ }^{30}$ Egz. HAB, sygn. M: Tl 181.

${ }^{31}$ Ch. Weismann, Die Katechismen des Johannes Brenz. 1. Die Entstehungs-, Text- und Wirkungsgeschichte, Berlin-New York 1990, s. 65.

${ }^{32}$ Die Evangelischen Kirchenordnungen des XVI. Jahrhunderts, t. 7: Niedersachsen, z. 2, cz. 1, Tübingen 1963, s. 363.

${ }^{33}$ John Calvin: a biography, red. T.H.L. Parker, London 1975, s. 86-88.

${ }^{34}$ Die Evangelischen Kirchenordnungen des XVI. Jahrhunderts, t. 11: Bayern, cz. 1, Tübingen 1961, s. 500-501.

${ }^{35}$ Die Evangelischen Kirchenordnungen..., t. 7, s. 600.

${ }^{36}$ Die Evangelischen Kirchenordnungen..., t. 11, s. 709.
} 
Dekalogu po czytaniu Ewangelii i wyznaniu grzechów albo po kazaniu spotykamy dość sporadycznie. Wspomina o tym w rozdziale Pasterstwo domowe i zbiorowe redaktor dwujęzycznego, polsko-litewskiego kancjonału, wytłoczonego w 1598 roku w Wilnie przez Stanisława Wierzejskiego nakładem wileńskiego pisarza ziemskiego Melchiora Pietkiewicza ${ }^{37}$, i Krzysztof Kraiński w Porządku nabożeństwa z 1614 roku $^{38}$.

Kontynuacją linii psałterzy heidelberskich była również chronologicznie bliska Psalmom Dawidowym edycja Bernharda Buyssa (zm. przed 1620) dla wspólnoty Düsseldorf Księstwa Bergu w Nadrenii (1612) ${ }^{39}$. Zawiera ona rozbudowaną część kancjonałową i osobny - dodatkowy rozdział Schöne tröstliche und einbrunstige Gebettlein. W tym wydaniu Ordynacja kościelna ukazała się w poprawionej wersji z 1601 roku $^{40}$. Jej bardziej szczegółowe porównanie z zamieszczonymi w Psalmach Dawidowych formami sprawowania sakramentów mogłoby rzucić więcej światła na bezpośrednie źródła druku Hünefelda.

Można wymienić wiele cech wspólnych Katechizmu Heidelberskiego w składzie Psalmów Dawidowych i właśnie linii heidelberskich psałterzy niemieckojęzycznych. Już w 1563 roku w wydaniu w ramach Kirchenordnung dla celów niedzielnego nabożeństwa katechizm został podzielony na 52 części; w 1573 roku znacznie rozbudowane zostały cytaty biblijne, wprowadzono podział nie tylko na kapituły, lecz również na wiersze ${ }^{41}$. W nadrukowanej zaś w Psalmach Dawidowych polskiej wersji katechizmu brak podziału na części i brak cytatów biblijnych, są tylko odsyłacze do poszczególnych ksiąg - tak samo jak w wydaniach z Herborn, Amberg, Neustadt i Düsseldorfu.

Z cytowanych wyżej uchwał synodalnych wynika, że inicjatywa przekładu Katechizmu Heidelberskiego należała do Jednoty Braci Czeskich i była związana - jak się wydaje - z powstającym prawie jednocześnie tłumaczeniem katechizmu na język czeski. Wydrukowano je nieco później w 1619 roku.

Znamienne jest to, że redaktorzy Psalmów Dawidowych z 1616 roku nie wiedzieli o już istniejącym od pewnego czasu przekładzie polskim.

${ }^{37}$ Polski z litewskim catechism albo Krotkie w iedno mieysce zebranie wiary [...], k. 28v. (egz. Gd.BM, sygn. Uph.0.4980).

38 [Raków: Sebastian Sternacki], s. 84 (egz. BN, sygn. XVII.3.2383).

${ }^{39}$ E. Grunewald, Lobwasser am Niederrhein. Die Düsseldorfer Ausgabe der "Psalmen Davids" von 1612 und ihre Quellen, w: Der Genfer Psalter und seine Rezeption..., s. 229-238. Przedruk współczesny: Das Düsseldorfer Gesangbuch von 1612, FaksimilieNachdruck, Köln-Bonn 1983.

${ }^{40}$ Die Evangelischen Kirchenordnungen..., t. 14, s. 556-603.

${ }^{41}$ H. Walter, op.cit., s. 38. 
Chodzi o łacińsko-polską edycję, która ukazała się drukiem w 1605 roku w Wilnie ${ }^{42}$. W Bibliografii polskiej Karola Estreichera wydanie to nie jest zidentyfikowane ${ }^{43}$. Zamieszczona w dodatkach do katechizmu Modlitwa nauczajacych w szkole (s. 177-185) i Modlitwa uczacych się w szkole (s. 185-189), a także brak jakichkolwiek form sprawowania sakramentów świadczą o tym, że owa edycja przeznaczona była wyłącznie do użytku szkolnego. Identyczny z wileńską wersją przekład wyszedł spod prasy Piotra Blastusa Kmity w 1621 roku w Lubczu. Do tej linii litewskiej należy również niedatowane wydanie z około połowy XVII wieku, poszerzone tylko o Piesn [...] o odpuszczenie grzechow i rozdział Upomnienia ludziom wszelkiego stanu stużace (s. 118-128), czyli Tablice domowa, obecną w większości wydań Katechizmu Heidelberskiego ${ }^{44}$.

W literaturze można spotkać przypuszczenie o jeszcze wcześniejszym powstaniu wersji polskiej. Tłumaczenie jest przypisywane kalwińskiemu ministrowi w Radziejowie i superintendentowi na Kujawach Andrzejowi Prażmowskiemu (zm. 1592) ${ }^{45}$. Wspomina o tym Andrzej Węgierski (1600-1649) w swojej historii reformacji, datując ogłoszenie katechizmu na 1564 rok $^{46}$. Edycję $\mathrm{z}$ tegoż roku wymienia na początku XVII stulecia również kancjonał Psalmy Dawidowe z hymnami ${ }^{47}$. Żaden egzemplarz tego wydania (rękopisu?) nie jest obecnie znany. W tym wypadku chodziło być może o inny druk krakowski - Kathechizmus, to iest, sposob nauczania y ćwiczenia dziatek w prawdziwey y ssczyrey naucze Krześsijańskiey vczyniony na kstałt rozmowy, opublikowany w tym samym 1564 roku w oficynie Macieja Wirzbięty ${ }^{48}$. Z całą pewnością za-

${ }^{42}$ Catechesis Religionis Christianae. Latine et Polonice recens edita, Vilnae [b. dr.] (egz. BUW, sygn. Sd.711.167).

${ }^{43}$ K. Estreicher, Bibliografia polska, t. 14, Kraków 1895, s. 94.

${ }^{44}$ Egz. BJ, sygn. 42308-I.

45 M. Sipayłł, Prażmowski (Prasmovius) Andrzej, w: Polski słownik biograficzny, t. 28, Kraków 1985, s. 350-351.

${ }^{46}$ A. Wengerscii, Libri quattuor Slavoniae reformatae, przedmowa I. Tazbir, Warszawa 1973 , s. 407.

47 „Na trzecim mieyscu położone są Katechizmy [...] drugi więtszy dla roślieyszych tak młodzieńcow jako y Panien [...] ten Katechism in Palatinatu wydany wszytkie Ewangelickie prawowierne zbory w Niemcech y w Niderlancie / do szkoł / y kościołow przyjęły: ten jeszcze roku Pańskiego 1564 we zborze Radziejowskim przetłumaczony / y w Krakowie drukowany był / Na ten Katechizm wykłady uczone wydali D.Ursinus, ktory wypolerował Paraeus, Bastingius, Lanspergius, Milius, Sibrandus y inszy ludzie zacni. Ten przy Psałterzach y Kancionałach Niemieckich wszędy położony znaydziesz" (Gdańsk, A. Hünefeld, 1619, k. 8-8v.; egz. BN, sygn. XVII.2.326).

48 Zob. M. Korzo, Jeszcze raz w sprawie nieznanego ttumaczenia Jana Kalwina w Polsce, „Odrodzenie i Reformacja w Polsce” 2012, t. 56, s. 192-202. 
tem można twierdzić, że najwcześniejszy przekład Katechizmu Heidelberskiego powstał właśnie w Jednocie Litewskiej. Jego podstawą mogło być niepołączone ani z ustawą kościelna, ani z psałterzem wydanie łacińskie. Dopiero dziesięć lat po ukazaniu się druku wileńskiego dochodzi do kolejnej inicjatywy wydawniczej. Bracia czescy sięgają tym razem po niemiecką wersję katechizmu. Wynika z tego, że przedstawiciele różnych odłamów reformacyjnych w Rzeczypospolitej nie zawsze byli dobrze obeznani ze wzajemnym dorobkiem wydawniczym, nawet gdy chodziło o podstawowe dokumenty zawierające doktrynę reformowanego chrześcijaństwa.

W latach późniejszych Katechizm Heidelberski zadomawia się w Rzeczypospolitej na stałe. Spotykamy jego liczne przedruki w kancjonałach polskich i litewskich, a także wydanych "za zgodą wszystkich zborów”; staje się on również podstawą nauczania zarówno w jednotach reformowanych, jak i u braci czeskich. Wileński synod prowincjonalny z 1629 roku nakazuje w kanonie 21, aby „in Catechesi Palatinatus [...] ćwiczeni byli dexterime, mniejsi zaś in Catechesi nostra minori" ${ }^{49}$. O realizacji tych uchwał świadczą programy nauczania z tegoż roku w starszych klasach gimnazjum w Kiejdanach ${ }^{50}$. O używanie Katechizmu Heidelberskiego w Jednocie Braci Czeskich zatroszczył się już synod w Ostrorogu (12-17 października 1618), określając go jako „katechizm duży” (,Die klein und groß Cathechismen lehren" ${ }^{51}$ ). W Lesznie za czasów Jana Komeńskiego, około 1637 roku, wykładany był już nie tradycyjny mały katechizm, sięgający początków XVI stulecia, lecz wyłącznie Katechizm Heidelberski. Wkrótce zaprzestano w Lesznie używania starych katechizmów czeskich ${ }^{52}$.

49 Akta synodów prowincjonalnych Jednoty Litewskiej 1626-1637, wstęp, oprac. M. Liedke, P. Guzowski, Warszawa 2011, s. 54.

50 S. Tworek, Programy nauczania i prawa gimnazjum kalwińskiego w Kiejdanach z lat 1629 i 1685, „Odrodzenie i Reformacja w Polsce” 1970, t. 15, s. 226-227.

51 Akta synodów różnowierczych..., s. 277.

52 J. Dworzaczkowa, Szkoła w Lesznie do 1656 roku. Nauczyciele i programy, Leszno 2003, s. 70. 


\title{
MARGARITA A. KORZO \\ David's Psalms (Gdańsk 1616): a contribution to the reception of the Heidelberg Catechism in Poland
}

\begin{abstract}
Aвstract. This article attempts to reconstruct the circumstances surrounding the origination and the possible sources of the catechism included in the edition of $D a$ vid's Psalms (Danzig 1616), i.e., the so-called Heidelberg Catechism, also known as the Palatinate catechism, published in 1563. During the translation work, Polish editors made an extensive use of the series of other the so-called Heidelberg Psalters (Heidelberg 1567, 1573, 1575; Neustadt 1584; Herborn 1595, 1598, 1609; Amberg 1604 and Düsseldorf 1612) that included the German language version of the Geneva psalter authored by the translator and the law reader at the University of Königsberg Ambrosius Lobwasser (Leipzig 1573) combined with the abridged Church regulations for the Palatinate and a selection of prayers called the Heidelberg Catechism. The idea of the translation of the catechism was initiated by members of the Unity of the Brethren (Bohemian Brethren) who, at the time, were not aware of the already existing and widely used in practice Polish translation of the catechism (Vilna 1605). The above testifies to the fact that the representatives (members) of different factions and splinter groups of the Reformation groups in the Republic of Poland were not always well acquainted with the publishing output of their respective publishing endeavours. The Heidelberg Catechism, recommended by the synodal legislation, becomes in time the most fundamental publication for teaching in the Republic of Poland for both reformed unities and Bohemian brethren.
\end{abstract}

Key words: Reformation writings in Poland, A. Lobwasser psalter, Polish translations of the Heidelberg Catechism and their reception. 
